\title{
Novas Perspectivas para o Estudo da Relação entre Discursos Midiáticos, Juventude e Poder ${ }^{1}$
}

\author{
João Freire Filho² \\ Universidade Federal do Rio de Janeiro \\ jofreirefilho@hotmail.com
}

\begin{abstract}
Resumo: Na primeira parte deste artigo, examino, sob uma perspectiva genealógica, como as idéias ainda hoje preponderantes acerca da adolescência se tornaram possíveis e foram desenvolvidas, codificadas $e$ disseminadas na virada do século $X X$, no âmago de candentes debates sobre questões fundamentais para a estabilidade e o progresso dos Estados-Nação. Após este exercício histórico e teoricamente informado de desnaturalização e desconstrução do conceito de adolescência, passo a abordar certos desafios metodológicos que envolvem a análise da construção discursiva da adolescência e da juventude na mídia contemporânea e suas possíveis implicações no governo deste segmento populacional. Na conclusão do artigo, reflito sobre minhas próprias incursões neste campo de investigação pouco explorado pelos pesquisadores da área de comunicação social no Brasil.
\end{abstract}

Palavras-chave: Juventude; Mídia; Discurso; Poder; Metodologias de Pesquisa em Comunicação.

Resumen: En la primera parte de este artículo, examino desde una perspectiva genealógica como las ideas que todavía son predominantes acerca de la adolescencia se volvieron posibles y fueron desarrolladas, codificadas y difundidas en el cambio del siglo $X X$, en el centro de calurosos debates sobre cuestiones fundamentales para la estabilidad y el progreso de los Estados-Nación. Después de este ejercicio histórico y teóricamente informado de desnaturalización y desconstrucción del concepto de adolescencia, paso a tratar de algunos desafios metodológicos que envuelven el análisis de la construcción discursiva de la adolescencia y de la juventud en los mass media y sus posibles implicaciones en el gobierno de este segmento poblacional. En la conclusión del artículo hago uma reflexión sobre mis propios trabajos en este campo de investigación poco explorado por los estudiosos de la de comunicación social en Brasil.

\footnotetext{
${ }^{1}$ Este artigo apresenta reflexões de uma pesquisa em andamento financiada pela FUJB/UFRJ e pelo CNPq.

2 Jornalista, Doutor em Literatura Brasileira pela Pontifícia Universidade Católica do Rio de Janeiro e professor-adjunto da Escola de Comunicação da Universidade Federal do Rio de Janeiro, onde integra o NEPCOM (Núcleo de Estudos e Projetos em Comunicação) e coordena a Linha de Mídia e Mediações Socioculturais do Programa de Pós-Graduação.
} 
Palabras clave: Juventud; Mass Media; Discurso; Poder; Metodologías de Investigación en Comunicación.

\begin{abstract}
In the first part of this article I examine, under a genealogical perspective, how the still today predominant ideas concerning adolescence became possible and were developed, codified, and disseminated on the turn of the XXth century in the middle of intense debates on fundamental questions for the stability and the progress of the Nation-States. After this historical and theoretically informed exercise of denaturalization and deconstruction of the adolescence concept I start to approach certain methodological challenges that involve the analyses of the discursive construction of adolescence and the youth on contemporary media and their possible implication in the governance of this population segment. In the article conclusion, I offer a reflection upon my own incursions in this not very explored field of inquiry by the researches of the area of media studies in Brazil.
\end{abstract}

Keywords: Youth; Media; Discourse; Power; Communication Research Methods.

A despeito de sua aparente obviedade e solidez epistemológica, adolescência e juventude são conceitos complexos e historicamente instáveis, definidos e representados dentro de diferentes formações discursivas que circulam, colidem e articulam-se num determinado tempo e espaço. As artes, as indústrias da moda e da beleza, os conglomerados midiáticos globalizados, as ciências humanas e sociais entre outros discursos emergentes ou legitimados - produzem conhecimentos, verdades sobre o que constitui a "essência" e as "potencialidades", os "prazeres" e os “dilemas" dos adolescentes e dos jovens, como devemos interpretá-los e interpelá-los, no interior de configurações historicamente determinadas de saber, poder e subjetivação. ${ }^{3}$

3 Não existe consenso quanto às diferenças e aos nexos entre as noções de adolescência e
juventude. Nas esferas acadêmica e comercial, os dois termos são empregados, amiúde, de
forma intercambiável, sem maiores preocupações com a distinção conceitual; certos textos, 
Nos inúmeros relatos factuais e ficcionais do mundo adulto, a adolescência e a juventude figuram como importantes constructos discursivos, capazes de condensar e dinamizar expectativas e temores largamente difundidos acerca de mudanças na economia, nos hábitos e nos costumes, na moralidade e na sexualidade, na produção e no consumo cultural e nas relações sociais ("Você Precisa Da Nova Geração Para Entender A Cultura”, pontificou, a propósito, a propaganda do Folhateen, suplemento juvenil semanal da Folha de S. Paulo, em junho de 2005).

As diferentes (e até mesmo incompatíveis) versões da adolescência e da juventude formuladas no âmbito do Estado, do mercado, dos movimentos sociais e da ciência ajudam a moldar, remodelar e justificar sistemas de disciplina, práticas pedagógicas, rotinas familiares, programas e políticas que almejam regular as disposições, os comportamentos públicos e privados e as subjetividades ("provisórias", "parciais", "desejantes”) de moças e rapazes, assegurando sua adequada inserção na sociedade, como trabalhadores, chefes de família, donas de casa, cidadãos, consumidores, cidadãos-consumidores...

$\mathrm{Na}$ atualidade, a incessante produção de conhecimento intelectualmente embasado e a consolidação de novas especializações científicas como a hebiatria

entretanto, procuram sublinhar, por razões de ordem metodológica e/ou política, as particularidades dos dois marcos etários. De acordo com o esquema sintético de Frith (2005), a noção de adolescência é mais usada por autores especialmente interessados em salientar as alterações psicológicas associadas ao período da vida humana que sucede à infância; juventude seria um conceito mais flexível, cujos significados são mais responsivos à mudança social e mais sensíveis ao argumento político. De maneira análoga, Virgínia de Freitas (2006) observa que os psicólogos no Brasil convencionalmente lançam mão do termo adolescência quando desejam se reportar às transformações emocionais e comportamentais vivenciadas pelos indivíduos com a chegada da puberdade; sociólogos, demógrafos e historiadores, por sua vez, costumam optar pelo vocábulo juventude ao tratar de temas como as condições e possibilidades de participação dos jovens na conservação e na modificação da sociedade, a inclusão ou exclusão social dos diferentes subgrupos juvenis e a postulação do jovem como sujeito de direitos. Uma das tendências dentro dos debates sobre políticas públicas em nosso país é definir adolescência e juventude como dois momentos do período amplamente denominado juventude - a adolescência corresponderia, no caso, à primeira fase (que vai dos 12 aos 18 anos incompletos, segundo a faixa etária estabelecida pelo Estatuto da Criança e do Adolescente); a juventude (também qualificada de juventude propriamente dita ou pósadolescência) remeteria a uma etapa posterior, de construção de trajetórias de entrada na vida social (que se estenderia até os 24 anos de idade, consoante o critério firmado pelas Nações Unidas e pelo IBGE) (a respeito da "psicologização da adolescência" e da "sociologização da juventude", consultar, também, Abramo 1997, 2005, 2006; Sposito 2003; Dávila León 2004; Besley 2006). 
(ramo da pediatria cujo foco central é a prevenção e o tratamento de problemas físicos e emocionais "típicos dos adolescentes", como a obesidade, a anorexia, a vigorexia, a bulimia, a hiperatividade, a depressão, as tendências autodestrutivas, o alcoolismo, a toxicomania...) prometem tornar a adolescência e a juventude - em toda a sua diversidade e complexidade - apreensíveis e governáveis de modos cada vez mais refinados.

Na primeira parte deste artigo, examino, sob uma perspectiva genealógica, como as idéias ainda hoje preponderantes acerca da adolescência se tornaram possíveis e foram desenvolvidas, codificadas e disseminadas na virada do século XX, no âmago de candentes debates sobre questões fundamentais para a estabilidade e o progresso dos Estados-Nação. Meu relato histórico problematiza a visão dominante de que a adolescência constitui um fenômeno natural da espécie humana - um evento de origem biológica relativamente ignorado ou negligenciado durante a maior parte de nossa estada na Terra, mas que, no ambiente fremente do fin de siècle, foi "descoberto" pelos novos saberes científicos, passando a ser gerenciado em vários programas educacionais, legais e médicos. Preocupo-me, particularmente, em enfatizar as interconexões entre a constituição da figura do adolescente através de uma rede de práticas discursivas e não-discursivas e as diligências para a formação governamental de um determinado tipo de self, num contexto em que as ciências sociais e a psicologia ajudavam a tornar as qualidades interiores, pessoais dos indivíduos visíveis e significativas para a construção de uma nova sociedade moderna.

Ao longo desta breve revisão da produção seminal de verdades a respeito da adolescência (fomentada no bojo de diversos centros de expertise) e da operacionalização de projetos reguladores lastreados pelos conhecimentos peritos, o leitor decerto perceberá a ressonância da problematização foucaultiana do poder e do sujeito, desenvolvida nas influentes teorizações do pensador francês sobre o governo como "conduta da conduta" - uma maneira perspicaz de compreender as contínuas, calculadas e contingentes tentativas de administração, ajustamento e incitação de ações, pensamentos, comportamentos e disposições das populações através de vários domínios, em diversos níveis de prática. 
Após este exercício histórico e teoricamente informado de desnaturalização e desconstrução do conceito de adolescência (em que saliento a fragilidade e a eventualidade daquilo que se afigura como consistente, necessário, inevitável), passo a abordar certos desafios metodológicos que envolvem a análise da construção discursiva da adolescência e da juventude na mídia e suas possíveis implicações no governo deste segmento populacional. Na conclusão do artigo, reflito sobre minhas próprias incursões neste campo de investigação pouco explorado pelos pesquisadores da área de comunicação social no Brasil.

\section{Cartografias de uma Terra Selvagem}

Embora a adolescência tenha sido social e culturalmente demarcada antes do início da modernidade (Levi e Schmidt 1996a; Taddei 2001; Eisenbichler 2002), a linha entre a juventude e a maturidade se tornou mais refinada, vigiada e democraticamente aplicada na virada do século $\mathrm{XX}$, dentro das nações industrializadas ocidentais (Demos e Demos 1969; Bakan 1971; Gillis 1974; Kett 1977; Dyhouse 1981; Demos 1986; Springhall 1986; Hendrick 1990; Alaimo 1992; Mitterauer 1992; Neubauer 1992; Barrán 1996; Levi e Schmidt 1996b; Huerre 1997; Ruchat 2000; Thiercé 2000). Mudanças políticas e sociais configuraram novas prerrogativas e encargos para os jovens e para os adultos incumbidos de monitorar o seu processo de formação identitária e posicionamento social. Como parte da marcha rumo a uma nova sociedade moderna, acreditava-se que os cidadãos precisavam se tornar mais autodeterminados, individualizados e razoáveis. A adolescência se constituiu, então, num espaço social em que os adultos responsáveis confabulavam a propósito das características das pessoas na modernidade, preocupavam-se com os desdobramentos destas mudanças sociais e estabeleciam políticas e programas que contribuiriam para criar a ordem social e a cidadania modernas. Tratava-se, nos termos de Lesko (2001: 6), de um "espaço social conveniente e promíscuo" - ou seja, "um lugar acerca do qual as pessoas podiam se preocupar infinitamente, um espaço que adultos de toda parte podiam observar cuidadosamente e que podia ser imaginado como tendo muitas instabilidades visíveis e invisíveis".

Sob a égide de doutrinas positivistas e evolucionistas, biólogos, psicólogos, antropólogos criminais, profissionais de saúde, criminologistas, filantropos, 
trabalhadores sociais, legisladores e juízes delinearam a imagem da adolescência como um "problema", investindo sobre as mentes e os corpos pubescentes uma teia de análises, teorias, exames, exortações e injunções. Os mistérios e os caprichos deste intrigante intervalo etário mobilizaram a atenção loquaz não apenas dos "profissionais da juventude" (Gutton 1986), mas também de romancistas e pintores do fin de siècle (Neubauer 1992).

Como explicar tamanha explosão de elucubrações e representações sobre o "caráter" e a "fisiologia singular" do adolescente? Na realidade, pode-se dizer que a adolescência se convertera, naquela conjuntura finissecular, num "problema público" oportuno, cuja discussão incorporava outras preocupações comuns da época, como o progresso racial, o domínio masculino e a unidade e o poderio crescente das nações.

Em países economicamente avançados da Europa e nos Estados Unidos, a adolescência despontou como um fato social produzido por um conjunto de práticas materiais e educacionais que operavam tanto como uma tecnologia para regular a vida de rapazes e moças quanto para reforçar as normas sociais dominantes, num período de grande transição e incertezas. Uma gama de movimentos sociais e mecanismos institucionais (como o controle da sexualidade; a ampliação da educação compulsória, com a separação da grade curricular de alunos e alunas; o incentivo ao aprendizado de etiqueta, alta cultura e prendas do lar para as garotas; a organização de associações oficiais e voluntárias de lazer destinadas ao fortalecimento moral e corporal dos garotos; a edificação de cortes judiciais, reformatórios e prisões especialmente designadas para os jovens infratores) contribuiu para sacramentar a concepção da adolescência como uma fase qualitativamente distinta do desenvolvimento humano, situada entre a puberdade (uma ocorrência biológica concreta) e as idades especificadas por lei para a escolarização obrigatória, a entrada (sem restrições) no mercado de trabalho e o tratamento punitivo (sem atenuantes) da justiça criminal.

A "tecnologia da adolescência" (Lesko 2001, 2002) servia não somente para instruir os adolescentes a como se comportar, mas também para adestrá-los em quem se tornar - adultos devidamente escolados para participar, de forma genericamente propícia, na intricada vida social e econômica moderna. Os dispositivos institucionais e as estratégias discursivas que ambicionavam a formação 
governamental do "adolescente ideal" (sadio, higiênico, autodisciplinado, leal, disposto a aprender, desejoso de "fazer a coisa certa") acarretaram a instauração do seu doppelgänger, do seu duplo negativo - os "precoces", os "rebeldes", os "ociosos", os "delinqüentes", os "sexualmente desregrados", estigmas dos perigos latentes intrínsecos à adolescência e ao cotidiano das grandes cidades (Kett 1997; Gillis 1981; Perrot 2001; Kalifa 2002).

Numa atmosfera de obsessão pelas idéias cognatas do progresso e da decadência civilizacional (mensurados pelos novos conhecimentos científicos a respeito do desenvolvimento dos indivíduos e das sociedades), a adolescência se estabeleceu como lócus privilegiado para conjecturas, especulações e debates públicos acerca do futuro da raça e da nação. Nenhuma autoridade ou homem de idéias da época ousou negligenciar o tema: lideranças intelectuais e políticas, artistas e representantes das novas profissões científicas se interrogaram a respeito das práticas pedagógicas e dos procedimentos de gestão capazes de estimular certas aptidões e atributos (inteligência, educabilidade, estabilidade emocional) nos jovens e instilar nestes protocidadãos o desejo por uma ordem nacional e internacional apropriada, cuja defesa e perpetuação seria, ao fim e ao cabo, de sua responsabilidade.

Com uma extensão de tirar o fôlego, o subtítulo do seminal estudo efetuado pelo psicólogo norte-americano G. Stanley Hall, Adolescence: its psychology and its relation to physiology, anthropology, sociology, sex, crime, religion and education ([1904] 1981), não deixa dúvidas quanto à constituição da adolescência como um "artefato de governamentalidade", construído e operacionalizado na intersecção de uma variedade de disciplinas que definem o jovem como problema, vinculado principalmente ao trabalho social e ao reforço da lei. Ao longo das 1373 páginas dos dois volumes da pesquisa, Hall retoma reflexões e argumentos formulados em diferentes proposições filosóficas, fontes literárias e enunciados científicos; sua abordagem holística dos temas centrais da adolescência contempla uma estonteante mélange de tópicos: as mudanças biológicas da puberdade e sua caracterização précientífica na Grécia antiga; o desenvolvimento cerebral; os ritmos do sono; a saúde física; as transições sociais; as influências genéticas; o papel das mulheres como 
educadoras; os programas missionários religiosos, o aspecto poético do ato sexual... Etc. 4

O alentado tratado de Hall sistematizou e notabilizou a conceituação da adolescência como uma etapa natural (ainda que social e psicologicamente tumultuada) de transição da infância para a maturidade, caracterizada por conspícuas transformações corporais e alterações de humor, pelo reconhecimento da sexualidade, pela busca de valores e identidades coerentes, por tensões geracionais e pela formação de novas relações sociais. A maturidade representa - dentro desta visão linear da idade e do desenvolvimento cognitivo, emocional e social - a resolução (no tempo e na seqüência apropriada) de questões fundamentais para a formação da personalidade, a solidificação de valores e a conquista da independência social e financeira. Trata-se, presumidamente, de um estado fixo e não problemático - uma condição de equilíbrio e completude, isenta de conflitos.

Enquadrados num sistema estrutural etário que os mantêm numa condição liminar, de falta ou ausência (sempre "um vir a ser"), na encruzilhada entre natureza e cultura, os jovens são confrontados com o padrão do "adulto normal" idealizado em diferentes correntes filosóficas do Iluminismo (do sujeito ético kantiano ao homo economicus da tradição utilitarista-liberal). Seu contraponto estrutural, portanto, é nada menos que o herói burguês estável, soberano, autônomo, seguro de si, empreendedor, capaz de definir suas próprias necessidades e de procurar satisfazêlas racionalmente, em contraste com a emotividade, a inconstância, a vulnerabilidade, a indolência e a irracionalidade de criaturas primitivas como os animais, os selvagens e as mulheres...5

\footnotetext{
4 Com o firme propósito de sedimentar a perspectiva interdisciplinar na investigação sobre a adolescência, Hall ambicionou instituir, entre 1909 e 1910, uma "sociedade das sociedades", capaz de congregar scholars e profissionais cujos saberes poderiam ser arregimentados em benefício das crianças e dos jovens. Nos dois encontros promovidos pelo autoproclamado "pai da adolescência”, estiveram presentes higienistas, arquitetos, pedagogos, especialistas em delinqüência juvenil e lingüística infantil, além de reformadores sociais de notável ascendência política, como a senhora Theodore Roosevelt (Youniss 2005: 360; a respeito da importância da obra de Hall, o primeiro estudioso a receber o título de Ph.D. em psicologia nos Estados Unidos, com mais de 350 trabalhos publicados, consultar também Grinder e Strickland 1968; Dahl e Hariri 2005; Shanahan et al. 2005).

5 Inspirado pelas teses evolucionistas do darwinismo biológico e social, Hall argumentara, a propósito, que "a adolescência não é apenas um tempo excitante e estressante de rápida mudança: ela representa a transição filética da animalidade pré-consciente para a
} 
Ao esmiuçar as conexões entre o discurso científico sobre a adolescência e o discurso colonialista, Lesko (2001) salienta, com acuidade, que as conceituações do jovem e do colonizado cristalizadas no fim-de-século escamoteiam contextos e constrangimentos institucionais e políticos, preferindo enfatizar alegadas deficiências ou má adaptações psicológicas como justificativa para a subordinação e a dependência. Não só os argumentos científicos que deram sustentação às expansões colonialistas eram igualmente apropriados para a construção do conhecimento científico sobre a adolescência - mecanismos institucionais similares foram mobilizados tanto para os jovens como para os nativos (diretrizes sexuais, educacionais, religiosas e governamentais desenvolvidas para "proteger" e "educar").

As páginas introdutórias de $L^{\prime}$ adolescence ([1943] 1965), do psicólogo francês Maurice Debesse, ratificam a pertinência da analogia acima. Na abertura desta obra de grande influência internacional (inclusive no Brasil), Debesse afirma que G. Stanley Hall - calçado com "as botas do explorador" - nos legara pistas cartográficas preciosas para futuras expedições ao obscuro, ao elusivo continente da adolescência:

O trabalho não está terminado. Ao debruçarmo-nos sobre uma carta da adolescência, percebemo-nos como diante das cartas da África dos meados do século passado, percebemo-nos da existência de vazios significativos. Além disso, nem todas as cartas concordam exatamente... Quer isto dizer que, ao lado das lacunas inevitáveis, há sem dúvida erros. Talvez novos trabalhos tragam sérias retificações. Desconfiemos, também aqui, das miragens, das falsas montanhas e dos rios misteriosos, como o Niger dos geógrafos do século XVIII (Debesse [1943] 1965: 19).

A descrição dos estágios do desenvolvimento humano formulada por Hall e seus epígonos mundo afora ajudou a sedimentar a concepção transhistórica e transcultural da adolescência, vinculada à noção de "crises necessárias", turbulências psicológicas e sociais inerentes à condição etária. Após examinar 2084 artigos publicados, entre 1985 e 1995, em seis expressivas revistas científicas especializadas no desenvolvimento humano (Adolescence; Child Development; Developmental Psychology; Journal of Adolescence; Journal of Early Adolescence; Journal of Youth

humanidade consciente" (18). Nos capítulos devotados à natureza e à educação das adolescentes, o perito acrescentou que as meninas jamais conseguiam ultrapassar, de fato, a adolescência, o que configurava o "seu charme, sua eterna feminilidade" (75). 
and Adolescence), Ayman-Nolley e Taira (2000) concluíram que a pesquisa psicológica revela uma patente obsessão pelo "lado sombrio da adolescência", descrita (sem o apoio ou a motivação de maiores evidências empíricas ou ponderações teóricas) como uma fase da vida em que prevalecem, de uma forma ou de outra, a sensualidade, o excesso, a desordem, os comportamentos de risco (o tom dos artigos se torna ainda mais aziago quando o foco são os adolescentes negros e hispânicos). No campo da psicologia do desenvolvimento, as atribulações da adolescência, como a irrupção da rebeldia e da sexualidade, costumam ser associadas ao influxo brutal dos hormônios; os sociólogos, por sua vez, tendem a ressaltar as incertezas relacionadas com mudanças sociais, como a entrada no mercado de trabalho ou a independência dos pais (Griffin 1993). ${ }^{6}$

Apesar das obstinadas tentativas de demarcação categórica da adolescência e da juventude em termos de peculiaridades (ou fragilidades) fisiológicas, psíquicas, sociais, não há consenso sobre o período de duração, os atributos e a significação destes estágios supostamente universais e evidentes da vida humana. Para grande parte dos jovens do planeta, a concepção clássica da juventude como um interregno entre a meninice, de um lado, e a entrada no mundo do trabalho, do outro, é totalmente inadequada - afinal, segundo documento da Organização Mundial do Trabalho divulgado em 1986, 50 milhões de crianças com menos de 15 anos tinham, naquele momento, vida laboral ativa (98\% delas residentes em países em desenvolvimento) (Wyn e White 1997: 10). Mesmo a biologia humana e a idade da puberdade se alteram ao longo do tempo e de acordo com o sexo, a classe social e o habitat geográfico; muitos dos traços psicológicos comumente atribuídos à adolescência ("tempo de crise"; "período de tempestades e transtornos"; "idade ingrata") são culturalmente específicos e apresentam-se de forma bastante diferenciada dentro das populações rurais e urbanas de uma mesma sociedade. A

${ }^{6}$ Conforme indica César (1998: 28-29), a problematização da adolescência ingressou relativamente tarde na órbita das preocupações científicas no Brasil, despontando em traduções de textos europeus e norte-americanos, no final dos anos 1920, e fortalecendo-se, a partir da década de 1950, com a produção nativa de manuais psicopedagógicos, bem como com a tradução massiva de obras estrangeiras. Além de incorporar a concepção da adolescência como "crise", atrelada às imagens de sexualidade e delinqüência, a produção brasileira seguiu à risca a estrutura da literatura científica importada: a mesma organização dos capítulos e forma de abordagem dos temas, dando ênfase invariavelmente à normalização da conduta física, psíquica, social e sexual. 
saída de ou a entrada em determinadas instituições, como a família e o matrimônio, constituem marcos igualmente problemáticos de emancipação - além da notável diversidade de faixas etárias em que os indivíduos contraem núpcias, o casamento, em algumas culturas, não envolve necessariamente a diminuição da autoridade patriarcal (Mitterauer 1992: 2-11).

\section{A Trama dos Estereótipos}

Os conceitos psicológicos e sociológicos preponderantes em relação à posição do jovem na sociedade retiram a possibilidade de este segmento da população representar a si mesmo nas instituições do mundo adulto, em função de sua inerente incompetência social e/ou cognitiva. Desencorajada (ou impedida) de produzir e circular amplamente representações alternativas e menos previsíveis de suas "identidades" e seus "melhores interesses", a juventude é constituída pelos discursos políticos, acadêmicos, midiáticos e corporativos como questão de Estado ou ideal de mercado - foco de espetáculos, temores e desejos para audiências massivas, compostas não só de jovens mas também de adultos.

São palpáveis e prósperos, na atualidade, os investimentos de todo o aparato da cultura da mídia e do consumo na configuração de interpretações e perfis específicos da adolescência e da juventude - como índice de normas ou patologias sociais, como ícones das bem-aventuranças ou mazelas do capitalismo globalizado... Anúncios, filmes, desenhos animados, canções, videoclipes, romances, seriados, sitcoms, noticiários e programas de auditório da TV, publicações especializadas, reportagens e suplementos teen dos jornais de circulação nacional, matérias e edições especiais das grandes revistas de informação - entre outras produções e artefatos midiáticos (e suas inúmeras mercadorias derivadas) - alegam representar ("narrar", "dramatizar", "encenar", "documentar", "reportar", "flagrar") as necessidades e as aspirações, os gostos e as atitudes, os direitos e os deveres, os modos de sentir e pensar dos jovens.

Sob a inspiração dos problemáticos rótulos geracionais, os "retratos da juventude" construídos nos espaços midiáticos (não raro, com o auxílio de pesquisas patrocinadas pelo mercado e/ou por universidades) tendem a homogeneizar gostos, experiências, problemas e expectativas de um grupo variado e desigual de pessoas da 
mesma faixa etária, negligenciando a diversidade de circunstâncias individuais e estratificações sociais que permeiam a vida das populações jovens.7 Atitudes, estilos, comportamentos e atividades de determinados segmentos ou grupos em uma situação social concreta (por exemplo, a prática de esportes radicais, as visitas assíduas aos shopping centers ou a estreita familiaridade com as novas tecnologias da comunicação) se tornam um dado estatístico e, eventualmente, um apanágio da juventude em geral.

Quando registradas por estes scripts unidimensionais da adolescência e da juventude, as diferenças são filtradas e administradas como índices de moda, tendência e estilo, em consonância com a taxonomia adotada por profissionais da publicidade interessados em definir segmentos de mercado de uma maneira mais requintada do que aquela oferecida por levantamentos demográficos, verificando como a ligação (ainda que efêmera) com certos "estilos de vida" ou "tribos urbanas" influencia tanto os padrões de consumo como o processamento de diferentes formas de ação de marketing.

Diante da popularidade mercadológica e das implicações políticas destes empreendimentos midiáticos, é surpreendente a escassez de estudos acadêmicos que abordem, dentro do campo da comunicação social no Brasil, as representações e os discursos (imagens, descrições, explanações, quadros de entendimento) sob a influência crescente dos quais adolescentes e adultos constroem os significados e a experiência da juventude na contemporaneidade - como ela é, por que ela é desta maneira e quais as suas conseqüências (os seus benefícios e riscos, vícios e virtudes) do ponto de vista individual e social. ${ }^{8}$

\footnotetext{
7 Como observa Lesko (2001: 4), o senso comum e o discurso científico costumam encarar os adolescentes como sendo menos individualizados do que os adultos, mais fortemente orientados pelas idéias e influências do seu grupo de pares. Antes de esta característica ser atribuída aos jovens, os psicólogos vitorianos haviam afiançado que mulheres, primitivos e crianças são mais semelhantes, mais genéricos, mais uniformes do que os homens (brancos, europeus) adultos.

${ }^{8}$ Num levantamento preliminar de textos de pesquisadores da área de comunicação social centralizados na representação midiática da adolescência ou da juventude, foram encontrados apenas os artigos de Borges (2005) e Gumes (2005), as dissertações de mestrado de Gobbi (1999), Borges (2003), Cury (2003), Quaresma da Cunha (2003), Remonte (2003) e Gumes (2004) e a tese de doutorado de Iwancow (2003). Outros trabalhos que gravitam em torno desta temática foram produzidos no âmbito da antropologia, educação, história,
} 
Ao abordar este tema raramente investigado, é necessário cautela para evitar certas armadilhas teóricas e metodológicas tão comuns nos estudos de representação das minorias (Freire Filho 2005a). Os trabalhos pioneiros sobre a estereotipagem de raça e gênero na mídia, por exemplo, foram bastante prejudicados pelo uso - sem maiores problematizações - da análise de conteúdo como ferramenta metodológica. Limitadas, em geral, a levantamentos amplos, objetivos e sistemáticos, as abordagens deste tipo se concentram em definir categorias de análises e estabelecer a freqüência, os papéis e outras características da representação dos grupos oprimidos.

Um estudo efetivo sobre as representações da adolescência e juventude na mídia não deve restringir-se ao mero levantamento estático de figurações estereotipadas, sem maior embasamento histórico e teórico; é fundamental se interrogar sobre a genealogia destas imagens social e politicamente motivadas, em que redes discursivas se inserem, por que perduram e, finalmente, como vêm sendo (ou devem ser) criticadas.

Não é o caso, evidentemente, de propor a aferição e o questionamento da acurácia referencial dos relatos midiáticos do fenômeno da adolescência, com a finalidade de resgatar a "autêntica natureza" ou os "verdadeiros ideais" dos jovens, presumidamente evadidos, distorcidos nos meios de comunicação de massa. Ou, como diria Foucault (1997a), não se trata de tentar reconstituir o que o referente juventude poderia ser em sua forma ou seu estado fundamental e discernir como ele foi organizado ("traduzido, deformado, travestido, talvez até mesmo reprimido") por discursos e pelo jogo oblíquo, enredado de suas operações, a fim de desvelar e libertar da "tirania do texto" estas experiências "pré-discursivas". A despeito de todas as suas boas intenções, tal abordagem acaba incidindo no erro de reproduzir a perspectiva essencialista criticada nos parágrafos anteriores.

psicologia e sociologia (Teodoro da Silva 1995; Alvim e Paim 2000; Benevutto 2000; Machado 2000; Paim 2002; Lima 2004; Menandro 2004; Nazareth 2004; Fischer 1996). Na obtenção destes dados, contei com a colaboração da bolsista de iniciação científica Ana Carolina Bento Ribeiro e da orientanda de mestrado Fernanda Marques Fernandes. Fontes consultadas: SciELO Brasil Site (http://www.scielo.br/); Banco de Teses da CAPES (http://www.capes.gov.br/capes/portal/Teses Dissertacoes.htm); revistas Comunicação e Educação (set. 1994 / dez. 2005); Comunicação e Sociedade (jul. 1979 / set. 2004); Contemporanea (dez. 2003 / dez. 2005); ECO-PÓS (jul. 2002 / jul. 2005); E-Compós (dez. 2004 / abr. 2006); Famecos (set. 1994 / dez. 2005); Fronteiras (jan. 2004 / dez. 2005); Revista Brasileira de Ciências da Comunicação (2000 / jun. 2006). 
Em vez de pretender elaborar respostas cabais, de dimensão ontológica, para as perguntas correlatas “O que é a adolescência?” ou “O que significa ser jovem?”, o esforço analítico deve se deslocar para um outro rol de questões fundamentais interrelacionadas: Como os discursos midiáticos operam na definição de determinados modos de ser adolescente ou jovem no Brasil do novo milênio? Articulados com que investimentos e preocupações sociais? Que aptidões e condutas das novas gerações são valorizadas? Quais são apontadas como problemáticas? Com base em que verdades e autoridades? Que ambivalências, tensões e contradições são possíveis detectar no interior destas representações midiáticas? Meu intuito, na verdade, é tentar explicar como emergem na mídia retratos particulares das novas gerações (em vez de outras versões possíveis) e a sua relação com discursos e práticas materiais engendradas em diferentes esferas institucionais.

\section{Considerações Finais: Decifrando o Poder do Banal}

Fiel ao protocolo analítico alinhavado acima, examinei, em trabalhos anteriores (Freire Filho 2005b, 2006), a construção discursiva das "adolescentes da nova geração" na mais longeva e comercialmente bem-sucedida de nossas revistas femininas juvenis: a Capricho. Embora a leitura de revista seja, por natureza, uma atividade solitária, Capricho e similares objetivam congregar as adolescentes em torno da participação em uma comunidade imaginária, propiciando-lhes identificações, apoio psicológico e sentimento de pertencimento. Suas matérias e seus anúncios geram a sensação reconfortante de que todas as jovens compartilham dos mesmos problemas e expectativas. O impacto da mídia é sempre mais visível e passível de reprovação quando o público parece adotar avidamente atitudes e modismos preconizados pelos textos comerciais. O poder das revistas femininas juvenis se torna muito mais penetrante, conduto, quando elas atuam no sentido de definir a natureza, as agruras e o vigor da adolescência feminina (sua genuína realidade, enfim), por meio de processos discursivos que priorizam questões, categorizam experiências e reembalam valores e modos de ser hegemônicos de maneira relevante para suas leitoras. Editoriais, artigos, reportagens, entrevistas, depoimentos, testes, dicas, concursos e propagandas fixam, num tom prazenteiro, as fronteiras do sucesso e do fracasso, do normal e do patológico, do consumismo sadio 
e da oneomania, da magreza modelar e da anorexia, da liberdade sexual e da libertinagem temerária.

Tais construções identitárias estão fortemente ligadas, por sua vez, a discursos produzidos em outras esferas da sociedade. Conforme assinala Macdonald (2003), os meios de comunicação de massa devem ser conceituados, no máximo, como "motivadores parciais de idéias e valores" ("partial originators of ideas and values") (p. 2). As demandas da audiência, dos anunciantes, dos contadores, dos profissionais de marketing, publicidade e promoção, entre outros grupos de pressão, concorrem para que a criatividade dos profissionais da mídia resida mais em manejar discursos pré-existentes e rivais do que em inventá-los pura e simplesmente.

As representações da adolescência e juventude na mídia se fundamentam em e são reguladas por discursos que, de fato, circulam, colidem e inter-relacionamse em diversos contextos e instâncias. Em sua tese de doutorado, Chaves (2005) identificou seis formações discursivas nas quais se apóiam as representações sociais da juventude na Argentina urbana contemporânea: o discurso naturalista; o discurso psicologista; o discurso da patologia social; o discurso do pânico moral; o discurso culturalista; o discurso sociologista. Não há o que se objetar quanto à validade geral da listagem fornecida pela autora; em estudos de caso mais específicos, porém, não se pode ignorar a presença de outros discursos igualmente influentes. Sendo assim, na fase inicial de minha própria pesquisa, procurei esmiuçar as conexões entre as representações de garotas autênticas e superpoderosas nas páginas da Capricho (animadas pela retórica pretensamente emancipatória e empoderadora do "seja diferente. seja você”) e os discursos cognatos do pós-feminismo e do consumismo (Freire Filho 2005b).

Atualmente, venho refletindo, de forma mais meticulosa, sobre a relação entre a versão específica de "liberdade" propagada pela revista e novas formas de controle social. Com o auxílio de autores que trabalham com a teoria da governamentalidade (Burchell et al. 1991; Barry et al. 1996; Rose 1998, 1999, 2005; Tait 2000; Bratich et al. 2003; Dean 2004), tenciono demonstrar como as publicações endereçadas às adolescentes formam um elo efetivo entre imperativos governamentais que têm por objetivo a construção de sujeitos condizentes com valores e propósitos do neoliberalismo (entendido, aqui, menos como uma filosofia 
de governo e democracia baseada na redefinição do Estado e na defesa do livremercado do que como uma racionalidade governamental para um arranjo social que se apóia em novos tipos de cidadãos-consumidores e novas técnicas para governá-los em termos de sua liberdade, autonomia e escolha) e as práticas concretas por meio dos quais estes imperativos são operacionalizados.

Estes imperativos governamentais que visam à condução da conduta das adolescentes não se realizam pelo poder de um decreto-lei, de forma ostensivamente repressiva. As estratégias discursivas empregadas para recrutar as adolescentes para os programas de auto-reforma são deveras sutis. De acordo com o discurso da Capricho, as jovens leitoras podem e devem definir que tipo de vida querem levar, necessitando, para isso, assumir uma atitude auto-reflexiva e de automonitoramento no tocante à sua identidade, à sua aparência, ao seu estilo de vida. Tal perspectiva se evidencia nas atitudes apregoadas em relação ao corpo, no fomento de uma cultura somática em que os corpos malhados e amimalhados aparecem como contingentes projetos individuais inacabados que requerem constante cuidado, renovação e preocupação, sobretudo autodisciplina e prevenção do risco. As jovens são encorajadas a embarcar neste escrutínio sistemático e incessante de todos os aspectos de si mesmas (suas medidas corporais, seu corte de cabelo, sua maquiagem, seu vestuário, seus hábitos, suas opiniões, suas escolhas, suas fantasias...) pela promessa de tornarem-se, ao mesmo tempo, emocional e sexualmente saudáveis; pessoalmente únicas, autênticas e socialmente normais, ajustadas; populares entre os colegas ("uma celebridade na sua turma") e atraentes para os garotos ("sexy sem ser vulgar").

Não se pode, é claro, presumir e proclamar que todas as jovens se comportarão necessariamente de acordo com as prescrições e proscrições formuladas, de maneira explícita ou tácita, pela mídia impressa especializada. A consistência do detalhamento de identidades e práticas de autoformação não implica coerência na resposta das leitoras, que podem utilizar, alterar, satirizar, adaptar, adotar parcial ou esporadicamente ou ignorar inteiramente modelos identitários e tecnologias de si divulgadas pelas revistas. Este rol de possibilidades não significa, como argumenta Tait (2000), que tais manuais de autoformação sejam malsucedidos, mas sim que a relação entre o seu conteúdo e desdobramentos práticos específicos é complexa e contextual. 


\section{Referências:}

ABRAMO, Helena Wendel. Considerações sobre a tematização social da juventude no Brasil. Revista Brasileira de Educação, nº 5-6, p. 25-36, 1997.

A condição juvenil no Brasil contemporâneo. In: ABRAMO, Helena Wendel e BRANCO, Pedro Paulo Martoni (orgs.). Retratos da juventude brasileira: análises de uma pesquisa nacional, p. 37-72. São Paulo: Editora Fundação Perseu Abramo/Instituto Cidadania, 2005.

. O uso das noções de adolescência e juventude no contexto brasileiro. Disponível em http://www.acaoeducativa.org.br/downloads/caderno JUV final.pdf. Acessado em março de 2006.

ALAIMO, Kathleen. Shaping adolescence in the popular milieu: social policy, reformers and French youth, 1870-1920. Journal of Family History, vol. 17, $\mathrm{n}^{0} 4$, p. 419-438, 1992.

ALVIM, Rosilene e GOUVEIA, Patrícia. Os jovens suburbanos e a mídia: conceitos e preconceitos. In: ALVIM, Rosilene e GOUVEIA, Patrícia (orgs.). Juventude anos 90: conceitos, imagens, contextos, p. 13-34. Rio de Janeiro: Contra Capa, 2000.

AYMAN-NOLLEY, Saba e TAIRA, Lora L.. Obsession with the dark side of adolescence: a decade of psychological studies. Journal of Youth Studies, vol. $3, \mathrm{n}^{\mathrm{0}} 1$, p. 35-48, 2000.

BAKAN, David. Adolescence in America: from idea to social fact. Daedalus, vol. 100, p. 979-995, 1971.

BARRÁN, José Pedro. El adolescente, ¿̇una creación de la modernidad? In: BARRÁN, José Pedro et al. (eds.), Historias de la vida privada en el Uruguay. El nacimiento de la intimidad (1870-1920), tomo 2, p. 175-199. Montevideo: Taurus, 1996.

BARRY, Andrew et al. (eds.). Foucault and political reason: liberalism, neoliberalism, and rationalities of government. Chicago: University of Chicago Press, 1996.

BENEVUTO, Mônica Aparecida. Mitos e imagens nos modos de expressão de jovens rurais. In: ALVIM, Rosilene e GOUVEIA, Patrícia (orgs.). Juventude anos 9o: conceitos, imagens, contextos, p. 133-157. Rio de Janeiro: Contra Capa, 2000.

BESLEY, Tina. Counseling youth: Foucault, power and the ethics of subjectivity. Rotterdam: Sense Publishers, 2006.

BORGES, Luís Fernando Rabello. O processo inicial de formulação de produtos de mídia impressa brasileira voltados ao público jovem - um estudo de caso da revista Pop. Dissertação de Mestrado. Universidade do Vale do Rio dos Sinos. Ciências da Comunicação. 2003.

Revista Pop e suas páginas coloridas: consumo e estética. ECO-PÓS, vol. 8, no 1, p. 86-99, 2005. 
BRATICH, Jack Z. et al. (eds.). Foucault, cultural studies and governmentality. Albany: State University of New York Press, 2003.

BURCHELL, Graham et al. (eds.). The Foucault effect: studies in governmentality. Chicago: Chicago University Press, 1991.

CÉSAR, Maria Rita de Assis. A invenção da "adolescência" no discurso psicopedagógico. Dissertação de Mestrado. Universidade Estadual de Campinas. Faculdade de Educação. 1998.

CHAVES, Mariana. Juventud negada y negativizada: representaciones y formaciones discursivas vigentes en la Argentina contemporánea. Ultima Década, $\mathrm{n}^{\mathrm{0}} 23, \mathrm{p}$. 9-32, 2005.

CURY, Lilian. O sentido de juventude em jornais diários: leitura de textos jornalísticos de cadernos de notícias locais de jornais diários paulistas. Dissertação de Mestrado. Universidade de São Paulo. Departamento de Ciências da Comunicação. 2003.

DAHL, Ronald E. e HARIRI, Ahmad R. Lessons from G. Stanley Hall: connecting new research in biological sciences to the study of adolescent development. Journal of Research on Adolescence, vol. 15, $\mathrm{n}^{\circ}$ 4, p. 367-382, 2005.

DÁVILA LEÓN, Oscar. Adolescencia y juventud: de las nociones a los abordajes. Última Década, vol. 12, n ${ }^{\circ}$ 21, p.83-104, 2004.

DEAN, Mitchell. Governmentality: power and rule in modern society. London: Sage, 2004.

DEBESSE, Maurice. A adolescência. Lisboa: Europa-América, 1965 [1943].

DEMOS, John. Past, present and personal: the family and the life course in American history. New York: Oxford University Press, 1986.

DEMOS, John e DEMOS, Virginia. Adolescence in historical perspective. Journal of Marriage and the Family, vol. 31, p. 632-638, 1969.

DYHOUSE, Carol. Girls growing up in late Victorian and Edwardian England. London: Routledge \& Kegan Paul, 1981.

EISENBICHLER, Konrad (ed.). The premodern teenager: youth in society 11501650. Toronto: Centre for Reformation and Renaissance Studies, 2002.

FISCHER, Rosa Maria Bueno. Adolescência em discurso: mídia e produção de subjetividade. Doutorado. Universidade Federal do Rio Grande do Sul. Educação. 1996.

FOUCAULT, Michel. A arqueologia do saber. Rio de Janeiro: Forense Universitária, 1997a.

. Microfísica do poder. Rio de Janeiro: Edições Graal, 2001.

FREIRE FILHO, João. Mídia, consumo cultural e estilo de vida na pós-modernidade. ECO-PÓS, vol. 6, n 1, p. 72-97, 2003 b.

Força de expressão: construção, consumo e contestação das representações midiáticas das minorias. Famecos, $\mathrm{n}^{0}$ 27, p. 18-29, 2005 a. 
. Paradoxos da autenticidade: gênero, estilo de vida e consumismo nas revistas femininas juvenis. In: FREIRE FILHO, João \& HERSCHMANN, Micael (orgs.). Comunicação, cultura e consumo: a (des)construção do espetáculo contemporâneo, p. 119-134. Rio de Janeiro: E-papers, 2005b.

FRITH, Simon. Youth. In: BENNET, Tony et al. (eds.). New keywords: a revised vocabulary of culture and society, p. 380-382. Oxford: Blackwell, 2005.

GILLIS, John R.. Youth and history: tradition and change in European age relations, 1770-present. New York: Academic Press, 1974.

GOBBI, Maria Cristina. Na trilha juvenil da mídia impressa - identificação, perfil e análise dos suplementos para jovens veiculados nos jornais diários do Brasil. Dissertação de Mestrado. Universidade Metodista de São Paulo. Comunicação Social. 1999.

GRIFFIN, Christine. Representations of youth: the study of youth and adolescence in Britain and America. Oxford: Polity Press, 1993.

GRINDER, R. E. e STRICKLAND, Ch. E.. A significação social da obra de G. S. Hall. In: BRITTO, Sulamita de (org.). Sociologia da juventude I: da Europa de Marx à América Latina de hoje, p. 19-35. Rio de Janeiro: Zahar, 1968.

GUMES, Nadja Vladi Cardoso. RG: Jovem. Identidades, culturas juvenis, meios de comunicação e estilos de vida: uma análise do Caderno Folhateen, da Folha de São Paulo. Dissertação de Mestrado. Universidade Federal da Bahia. Programa de Pós-Graduação em Comunicação e Cultura Contemporânea. 2004.

Representações de juventudes urbanas no Folhateen - suplemento do jornal Folha de São Paulo. ECO-PÓS, vol. 8, nº 1, p. 100-117, 2005.

GUTTON, Phillipe. Le processus d'adolescence et ses catégories. In: PROUST, François (ed.), Les jeunes et les autres. Contribution des sciences de l'homme à la question des jeunes, vol. 1, p. 70-79. Vaucresson: CRIV, 1986.

HALL, G. Stanley. Adolescence: its psychology and its relation to physiology, anthropology, sociology, sex, crime, religion and education. Norwood: Telegraph Books, 1981 [1904].

HEBDIGE, Dick. Hiding in the light: on images and things. London: Routledge, 2002.

HENDRICK, Harry. Images of youth: age, class, and the male youth problem, 18801920. Oxford: Clarendon Press, 1990.

HUERRE, Patrice. L'Adolescence n'existe pas. Histoire des tribulations d'un artífice. Paris: Jacob, 1997.

IWANCOW, Ana Elisabeth. O comportamento jovem e o shopping center - um objeto para a publicidade. Tese de Doutorado. Universidade do Vale do Rio dos Sinos. Ciências da Comunicação, 2003.

KALIFA, Dominique. Archéologie de l'apachisme. Les représentations des peauxrouges dans la France du XIXe siècle. Le temps de l'histoire, $\mathrm{n}^{0}$ 4, 2002. 
Disponível em

http://rhei.revues.org/document51.html. Acessado em maio de 2006.

KETT, Joseph F. Rites of passage: adolescence in America 1790 to the present. New York: Basic Books, 1977.

LESKO, Nancy. Act your age!: a cultural construction of adolescence. New York: Routledge, 2001.

Making adolescence at the turn of the century: discourse and the exclusion of girls. Contemporary Issues in Comparative Education, vol. 2, $\mathrm{n}^{\mathrm{o}}$ 2, p. 182-191, 2002.

LEVI, Giovanni and SCHMITT, Jean-Claude (eds.). A history of young people in the West. vol. 1: ancient and medieval rites of passage. Cambridge, MA: Harvard University Press, 1997a.

. A history of young people in the West. vol. 2: stormy evolution to modern times. Cambridge, MA: Harvard University Press, 1997b.

LIMA, André Luiz. A juventude no texto literário e na indústria cultural. Dissertação de Mestrado. Pontifícia Universidade Católica do Rio de Janeiro. Educação. 2004.

MACHADO, Elielma Ayres. Retratos da juventude: imagens de juventude e violência no Rio de Janeiro. In: ALVIM, Rosilene e GOUVEIA, Patrícia (orgs.). Juventude anos 9o: conceitos, imagens, contextos, p. 35-58. Rio de Janeiro: Contra Capa, 2000.

MACDONALD, Myra. Exploring media discourse. London: Arnold, 2003.

MENANDRO, Maria Cristina Smith. Gente jovem reunida: um estudo de representações sociais da adolescência / juventude a partir de textos jornalísticos (1968/1974 e 1996/2002). Tese de Doutorado. Universidade Federal do Espírito Santo. Psicologia. 2004.

MITTERAUER, Michael. A history of youth: family, sexuality and social relations in past times. Oxford: Oxford University Press, 1992.

NAZARETH, Leila. O discurso da mídia sobre a adolescente grávida: uma análise de ideologia. Dissertação de Mestrado. Pontifícia Universidade Católica de São Paulo. Psicologia. 2004.

NEUBAUER, John. The fin de siècle culture of adolescence. New Haven: Yale University Press, 1992.

PAIM, Eugênia. Forever young - a apropriação da imagem da juventude pela propaganda brasileira. Comunicações do Iser, ano 21, p. 57-61, 2002.

PERROT, Michelle. Dans le Paris de la Belle Époque, les «apaches », premières bandes de jeunes. In: Les ombres de l'histoire. Crime et châtiment au XIXe siècle, p. 351-364. Paris: Flammarion, 2001.

QUARESMA DA CUNHA, Simone Maria. O jovem imaginado - a configuração de um grupo de pertencimento pela produção das revistas impressas dirigidas ao público juvenil, a partir de um estudo de caso da Revista MTV. Dissertação de 
Mestrado. Universidade do Vale do Rio dos Sinos. Ciências da Comunicação. 2003.

REMONTE, Jarbas Gomes. A linguagem corporal do adolescente no contexto da cultura midiática. Dissertação de Mestrado. Universidade Paulista. Comunicação. 2003.

ROSE, Nikolas. Inventing our selves: psychology, power and personhood. Cambridge: Cambridge University Press, 1998.

. Governing the soul: the shaping of the private self. London: Free Association Books, 1999.

. Powers of freedom: reframing political thought. Cambridge: Cambridge University Press, 2005.

RUCHAT, Martine. Désordre, passion, adolescence: histoire d'un concept. In: BAZILASCHE, Juvénal Balegamire e MARC, Pierre (eds), Adolescence: des clefs pour comprendre, p. 31-49. Lyon: Chronique sociale, 2000.

SANTOS, Rafael José dos. A publicidade e a representação da juventude - um estudo sobre os mecanismos da produção publicitária. Dissertação de Mestrado. Universidade Estadual de Campinas. Antropologia Social. 1992.

SPOSITO, Marilia. Os jovens no Brasil: desigualdades multiplicadas e novas demandas políticas. São Paulo: Ação Educativa, 2003.

SPRINGHALL, John. Coming of age: adolescence in Britain, 1860-1960. Dublin: Gill and Macmillan, 1986.

SHANAHAN, Michael J. et al. One hundred years of knowing: the changing science of adolescence, 1904 and 2004. Journal of Research on Adolescence, vol. 15, $\mathrm{n}^{\circ}$ 4, p. 383-394, 2005.

TADDEI, Ilaria. Fanciulli e giovani. Crescere a Firenze nel Rinascimento. Firenze: Olschki, 2001.

TAIT, Gordon. Youth, sex, and government. New York: Peter Lang, 2000.

TEODORO DA SILVA, Ana Cristina. “Teen”, um personagem contemporâneo. Representação juvenil na imprensa. Dissertação de Mestrado. Universidade Estadual Paulista Júlio Mesquita Filho/Assis. História. 1995.

THIERCÉ, Agnès. Histoire de l'adolescence (1850-1914). Paris: Belin, 2000. WYN, Johanna Win e WHITE, Rob. Rethinking youth. London: Sage, 1997.

YOUNISS, James. G. Stanley Hall: neither psychology alone nor basic research is sufficient. Journal of Research on Adolescence, vol. 15, $\mathrm{n}^{\circ}$ 4, p. 357-366, 2005. 